\title{
Inclusão e perspectivas de desenvolvimento da microempresa e empresa de pequeno porte no processo de compras governamentais na esfera federal
}

\author{
Inclusion and prospects for development of micro and small businesses in the \\ government procurement process at federal level

\section{L'inclusion et perspectives de développement des micro et petites entreprises dans le processus d'achat du gouvernement au niveau fédéral}

Inclusión y perspectivas para el desarrollo de micro y pequeñas empresas en el proceso de compras gubernamentales a escala federal

\author{
Marcos André da Silva Cunha* \\ (admmasc@gmail.com) \\ Cleonice Alexandre Le Bourlegat* \\ (rf25@ucdb.br)
}

Recebido em 12/12/2015; revisado e aprovado 25/03/2016; aceito em 15/04/ 2016

DOI: http:/ / dx.doi.org/10.20435/1984-042X-2016-v.17-n.3(05)

\begin{abstract}
Resumo: Este artigo aponta como as Micro e Pequenas Empresas estão sendo incluídas e apresentam perspectivas de usufruírem da oportunidade de ampliar sua participação em processos de licitação para compras públicas federais, por meio do Pregão Eletrônico, na vigência da Lei Complementar n. 123/2006 e da aprovação da nova Lei Complementar n. 147/2014. Considera-se que o avanço das políticas públicas de inclusão das Microempresas e Empresas de Pequeno Porte nas compras governamentais tem sido fundamental para a sustentabilidade delas e para o Desenvolvimento Local.
\end{abstract}

Palavras-chave: direito administrativo; compras governamentais; sustentabilidade.

Abstract: This article indicates how the Micro and Small Enterprises are being included and present perspectives from enjoying the opportunity to expand their participation in bidding processes for federal public procurement through the Electronic Trading, in the presence of Complementary Law n. 123/2006 and the approval of the new Complementary Law n. 147/2014. It is considere that the advancement of public policies for the inclusion of Micro and Small Businesses in government procurement has been key to its sustainability and local development.

Key words: administrative law; government procurement; sustainability.

Résumé: Cet article indique comment les micro et petites entreprises sont inclus et présentent des perspectives de profiter de la possibilité d'élargir leur participation aux processus d'appel d'offres pour les marchés publics du gouvernement fédéral, par le biais du commerce électronique, en présence de Loi complémentaire n. 123/2006 et l'approbation de la nouvelle loi complémentaire n. $147 / 2014$. On considère que la promotion des politiques publiques pour l'inclusion des micros et petites entreprises dans les marchés publics ont été la clé de sa durabilité et le développement local. Mots-clés: droit administratif; les marches publics; durabilite.

Resumen: En este artículo señala cómo están siendo incluidas las micro y pequeñas empresas y presentar perspectivas de disfrutar de la oportunidad de ampliar su participación en los procesos de licitación para la contratación pública federal através del Electrónico de Negociación en presencia de la Ley Complementaria n. 123/2006 y la aprobación de la nueva Ley complementaria n. $147 / 2014$. Se considera que el avance de las políticas públicas para la inclusión de micro y pequeñas empresas en la contratación pública han sido clave para su sostenibilidad y el desarrollo local.

Palabras clave: derecho administrativo; compras del sector público; sostenibilidad.

\footnotetext{
* Universidade Católica Dom Bosco (UCDB), Campo Grande, Mato Grosso do Sul, Brasil.
} 


\section{INTRODUÇÃO}

O presente artigo tem como objetivo apresentar e discutir, mediante contribuições do Direito Administrativo, como as Microempresas e Empresas de Pequeno Porte estão sendo incluídas e como apresentam perspectivas de usufruir da oportunidade de ampliar sua participação em processos de licitação para compras públicas na esfera federal por meio do Pregão Eletrônico, na vigência da Lei Complementar n. 123/2006 alterada pela Lei Complementar n. 147/2014.

Nas compras governamentais de bens e serviços, as contratações da Administração Pública, conforme bem se definiu na Constituição Federal, só podem ser efetuadas por meio de Processo Licitatório, no qual se deve resguardar igualdade de condições a todos os concorrentes (BRASIL, 1988, Art. 37, Inc. XXI).

Em nível federal, o Pregão Eletrônico tem-se mostrado como a principal modalidade utilizada, por trazer maior economia ao erário público e maior transparência às transações do gênero.

Por outro lado, o poder de consumo em bens e serviços pelo Estado vem sendo pensado como um importante indutor de políticas de desenvolvimento, desde que os procedimentos utilizados para as compras governamentais sejam bem conduzidos.

$\mathrm{O}$ interesse específico neste artigo é correlacionar o poder de compras governamentais com a inclusão das Microempresas e Empresas de Pequeno Porte como fornecedores, colocadas em pé de igualdade e de forma simplificada frente a empresas de porte mais amplo, à luz dos princípios do Direito Administrativo, com a finalidade de atender necessidades coletivas de interesse público.

O desenvolvimento deste artigo foi estruturado em três seções. Na primeira, procurou-se apresentar em que consiste e como funciona a Licitação e o Pregão Eletrônico no processo de compras governamentais.
Na segunda seção, a preocupação é esclarecer o uso do poder de compras como política de desenvolvimento das micro e pequenas empresas, apontando as proposições jurídicas que as beneficiam, suas origens nas décadas de 80 e 90 do século passado, assim como os avanços na virada do Milênio e as conquistas da Lei Complementar n. 123/2006 na sua inclusão em processos licitatórios governamentais.

A terceira e última sessão discute as novas perspectivas de participação das Microempresas e Empresas de Pequeno Porte nas compras governamentais, por meio das contratações públicas sustentáveis e com a aprovação da nova Lei Complementar n. 147/2014. E por fim, são colocadas as conclusões finais a respeito do que foi apresentado e discutido.

\section{LICITAÇÃOE PREGÃOELETRÔNICO NAS COMPRAS GOVERNAMENTAIS}

As compras governamentais vêm sendo discutidas por um conjunto de autores, em função não só do poder de influência que elas exercem na atividade econômica, como na indução de diversas formas de políticas públicas, por meio de compras estratégicas. O Instituto de Economia Aplicada (IPEA) (SQUEFF, 2014) define compras públicas como sendo o "processo por meio do qual o governo busca obter serviços, materiais e equipamentos necessários ao seu funcionamento em conformidade com as leis e normas em vigor".

As compras públicas, além de garantir o suprimento de bens e serviços para o funcionamento do Estado, podem servir como forma de aumentar a demanda, estimular a economia, gerar mais empregos para os setores marginais, proteger empresas nacionais ou micro e pequenos empreendimentos, diminuir disparidades regionais, induzir a produção sustentável, fomentar tecnologia, influir na inovação, entre outros. 


\subsection{Licitação}

A licitação é o procedimento administrativo constitucional utilizado pelos órgãos públicos na realização das compras governamentais. De acordo com o que foi estabelecido no artigo 22, XXVII da atual Constituição Federal, o procedimento administrativo, exceto raras exceções indicadas na Lei 8.666/93 (artigos 17, I e II, 24, 25 e 24 IX), é exigido para os entes públicos da Administração Direta (União, Estados Membros, Distrito Federal e Municípios) e da Administração Indireta (Autarquias, Empresas Públicas, Sociedades de Economia Mista e Fundações Públicas), para qualquer tipo de negócio a contratar. Na concepção de Gasparini (2006, p. 23), licitação consiste no:

[...] procedimento administrativo através do qual a pessoa a isso juridicamente obrigada seleciona, em razão de critérios objetivos previamente estabelecidos, de interessados que tenham atendido à sua convocação, a proposta mais vantajosa para o contrato ou ato de seu interesse.

Ainda que existam autores que aludam sobre a origem do processo licitatório no governo brasileiro desde 1860 , foi somente a partir de 1988 que esse processo se tornou constitucional, quando com princípios estabelecidos:

Art. 37. A administração pública direta e indireta de qualquer dos Poderes da União, dos Estados, do Distrito Federal e dos Municípios obedecerá aos princípios de legalidade, impessoalidade, moralidade, publicidade e eficiência e, também, ao seguinte:

XXI - ressalvados os casos especificados na legislação, as obras, serviços, compras e alienações serão contratados mediante processo de licitação publica que assegure igualdade de condições a todos os concorrentes com cláusulas que estabeleçam obrigações de pa- gamento, mantidas as condições efetivas da proposta, nos termos da lei, o qual somente permitirá as exigências de qualificação técnica e econômica indispensáveis à garantia do cumprimento das obrigações. (BRASIL, 1988).

No entanto, além daqueles princípios previstos na Constituição, segundo Meirelles (1998), outros foram acrescentados ao Processo Licitatório, no momento de sua regulamentação pela Lei 8.666/93 e suas alterações, tais como: procedimento formal (vincula-se às exigências legais), igualdade entre licitantes, publicidade, sigilo das propostas, vinculação ao edital, julgamento objetivo, adjudicação compulsória (não pode ser repassado a outra empresa) e probidade administrativa (conduta honesta e leal do administrador público).

Essa Lei também serviu para disciplinar os procedimentos a serem adotados pela Administração Pública nas contratações de serviços e compras ao longo de um processo licitatório, prevendo, ainda, casos de sua desnecessidade.

A finalidade foi tornar o procedimento licitatório mais transparente e possibilitar à entidade escolha da proposta mais vantajosa aos seus interesses, além de propiciar aos interessados igual oportunidade de participação no certame. Visa ainda garantir à Administração o fiel cumprimento dos contratos firmados consigo, estabelecendo exigências de qualificação técnica e econômica, previstas no artigo 37, inciso XXI da Constituição Federal.

\subsection{Pregão Eletrônico}

O Pregão, como mais uma modalidade de licitação, surgiu somente em 1997, portanto depois da Lei 8.666/93. De acordo com Scarpinella (2002), teria emergido na Lei Geral de Comunicações que criou a Anatel, sendo posteriormente estendido ao restante da Administração Pública. O Ministério do Planejamento define o pre- 
gão como a modalidade de licitação para aquisição de bens e serviços comuns em que a disputa pelo fornecimento é feita em sessão pública, por meio de propostas e lances, para classificação e habilitação do licitante com a proposta de menor preço.

O Pregão na forma presencial transcorre em sessão pública, ocasião em que ocorre a entrega de envelopes de proposta e de habilitação, seguida da oferta de lances verbais pelos candidatos, em acordo ao disposto na Lei n. 10.520/ 2002.

Já o Pregão no formato eletrônico como procedimento licitatório foi previsto no $\S 1^{\circ}$ do art. $2^{\circ}$ da Lei n. 10.520, de 17 de julho de 2002, regulamentado pelo Decreto n. 5.450, de 31 de maio de 2005 , com vigência a partir de $1^{\circ}$ de julho de 2005 e pelo Decreto n. 3.555, de 08 de agosto de 2000. A diferença do Pregão Eletrônico é que, nesse processo, o fornecedor encaminha sua proposta de preços por meio da Internet. Realiza-se esse procedimento na data e horário previstos em edital, quando se dá a abertura da sessão. A etapa competitiva de oferta de lances e o resultado ocorrem por meio eletrônico. De acordo com o Decreto n. 5.450/05, art. $4^{\circ}$, a exigência de uso do pregão, preferencialmente o eletrônico, ocorre para:

[...] entes públicos ou privados, nas contratações de bens e serviços comuns, realizadas em decorrência de transferências voluntárias de recursos públicos da União, decorrentes de convênios ou instrumentos congêneres, ou consórcios públicos.

O Pregão (presencial e eletrônico) apresentou para a Administração Pública uma forma de aperfeiçoamento do regime de licitações. Nessa modalidade, não se impõe limite de valor para contratações, e o preço pode cair em função dos lances, sendo feito com maior transparência e agilidade. Além de reduzir despesas e desburocratizar o processo, ampliam-se as oportunidades de participação de um conjunto maior de empresas e de vários portes, inclusive as Micro e Pequenas Empresas.

\subsection{Pregão Eletrônico praticado no portal de compras do Governo Federal - Comprasnet}

O Portal de Compras do Governo Federal- Comprasnet, gerenciado pelo Ministério do Planejamento, Orçamento e Gestão, tem funcionado como a plataforma para operar processos eletrônicos de aquisições, como também para disponibilizar informações relativas às licitações e contratações, promovidas pela Administração Pública Federal direta, autárquica e fundacional. Nesse portal, podem ser realizadas todas as modalidades de licitações previstas na Lei n. 8.666, de 21 de junho de 1993 (convites, tomadas de preço e concorrência), assim como os pregões e as cotações eletrônicas. Ainda se incluem as Intenções de Registro de Preços (IRP) e os contratos sob o Regime Diferenciado de Contratações Públicas (RDC). Os fornecedores fazem acesso a diversos serviços no referido portal, entre eles a inscrição no Sistema de Cadastramento Unificado de Fornecedores (Sicaf), informações sobre os editais e a participação nos Pregões Eletrônicos.

\subsubsection{Funcionamento do Pregão Eletrônico}

O Pregão Eletrônico possui uma fase preparatória e outra externa. A fase preparatória constitui-se das atividades de elaboração do termo de referência pelo órgão requisitante e aprovação pela autoridade competente da apresentação de justificativa da contratação, da elaboração do edital e exigências de habilitação, das sanções aplicáveis e da designação do pregoeiro e sua equipe de apoio.

Para participar de Pregão Eletrônico nos Órgãos Públicos Federais, a Pessoa Jurídica ou Pessoa Física cadastrada no Sistema de Cadastramento de 
Fornecedores - Sicaf se responsabiliza formalmente pelas transações efetuadas em seu nome; mediante recepção da chave de identificação e da senha de acesso intransferível, a pessoa credenciada pode acompanhar as operações no sistema eletrônico.

A fase externa do pregão eletrônico tem início com a publicação de aviso do edital. Os meios de divulgação variam de acordo com os valores estimados para sua contratação.

A sessão pública do Pregão Eletrônico é aberta na Internet por comando do pregoeiro que deve coordená-la. Ele faz isso mediante utilização do seu certificado digital e senha, na hora prevista no edital. Os participantes credenciados também acessam a sessão pública, por meio de sua chave de identificação e senha, na hora determinada. A partir de então, são encaminhados os lances sucessivos sempre inferiores ao último ofertado. A digitação do valor da proposta aparece num campo apropriado do sistema, sendo esse valor do lance por ele registrado.

Após o encerramento da etapa competitiva, o pregoeiro pode encaminhar, pelo sistema eletrônico, uma contraproposta ao licitante que tenha apresentado lance mais vantajoso, embora sem negociar condições diferentes daquelas previstas no edital. Constatado o atendimento às exigências fixadas no edital, inclusive o de habilitação, o licitante de melhor preço nas condições exigidas será declarado vencedor.

\section{O USO DO PODER DE COMPRAS COMO POLÍTICA DE DESENVOLVIMENTO DA MICRO E PEQUENA EMPRESA}

O uso de ferramentas eletrônicas para efeito de compras públicas foi considerado no início, apenas uma atividade-meio, entendido como busca de maior eficiência nos processos licitatórios. O princípio da eficiência, como princípio, já era previsto na Constituição.

O meio eletrônico permitia comprar mais rápido e melhor, pelo menor custo possível. No entanto, ao longo do tempo, foi se verificando que o uso dessas ferramentas de licitação, exatamente pelos seus métodos transparentes e ágeis e com igualdade de acesso a todos os participantes interessados em ser fornecedor, poderia direcionar políticas públicas de interesse nacional, especialmente aquelas de natureza inclusiva, sustentável e inovadora. O uso do poder de compras governamentais poderia, nesse sentido, focalizar segmentos estratégicos e relevantes para esse fim. Assim, de simples atividade-meio a Licitação por meio do Pregão Eletrônico foi se transformando em atividade-fim, de relevante interesse coletivo.

A inclusão de Micro e Empresas de Pequeno Porte passou a fazer parte de uma das finalidades das Compras governamentais pelo sistema de Pregão Eletrônico. Baseado em princípios e exigências legais, para esse segmento econômico empresarial da sociedade brasileira passou-se a criar alguns benefícios específicos.

Para isso contribuíram a Lei do Estatuto da Microempresa de 1984, a Constituição Federal de 1988, a Lei do SIMPLES de 1996 e suas posteriores modificações, mas principalmente a Lei Complementar n. 123 de 2006 e suas modificações, que atribuem tratamento diferenciado, simplificado e favorecido para essas empresas.

\subsection{Proposições Jurídicas que beneficiam as Micro e Pequenas Empresas}

A Lei Complementar n. 123/06, considerada a proposição jurídica mais importante na diferenciação e favorecimento da Microempresa (ME) e Empresa de Pequeno Porte (EPP) para sua manutenção no mercado, teve origem no contexto dado pelo final da década de 70 
e décadas de 80 e 90 . Mas o movimento do setor produtivo, que caracterizou a virada do novo Milênio, exerceu importante contribuição na sua elaboração e aprovação, para atribuir a esse segmento um tratamento jurídico diferenciado.

\subsubsection{Origens das proposições jurídicas} que beneficiam a Microempresa e a Empresa de Pequeno Porte na década de 80 e 90 do século XX

A Lei n. 7.256/84 foi a primeira a ser aprovada no sentido de estabelecer normas integrantes do Estatuto da Microempresa, relativas ao tratamento diferenciado e simplificado para fins de desenvolvimento desse segmento empresarial.

A referida lei foi criada num momento em que as multinacionais dotadas de grandes avanços tecnológicos se impunham num mercado oligopolizado de nível internacional, num mundo que já se mostrava organizado em rede.

Nesse contexto, o segmento que se mostrava mais vulnerável era o da Microempresa e Empresa de Pequeno Porte. Verificava-se, no entanto, que esse segmento mais vulnerável da economia brasileira, além de ser produtivo, não só exercia papel relevante na economia local como importante função social por ser grande geradora de empregos, fazendo-se necessário criar incentivos para sua manutenção e desenvolvimento conforme Mota Jr. (2007).

Desse modo, pode-se entender a aprovação da Lei n. 7.256, de 27 de novembro de 1984, ainda sob a égide da Constituição de 1967, durante o governo dos militares. Chamada de Estatuto da Microempresa, lei essa que atribuiu tratamento diferenciado, simplificado e favorecido, seja nos campos administrativo, tributário, previdenciário e trabalhista, como no campo creditício e de desenvolvimento empresarial.

Em 28 de março de 1994, foi promulgada a Lei n. 8.864, sem revogar a Lei n.
7.256/84, com a finalidade de ampliar os benefícios às pequenas empresas. Nela se facultava apenas ao microempresário eleger o regime que melhor thes aprouvesse.

Já os pequenos empresários poderiam optar apenas pela Lei n. 8.864/94. De acordo com Mota Jr. (2007), a Lei n. 9.841, de 5 de outubro de 1999, que criou o Estatuto da Microempresa e da Empresa de Pequeno Porte, dirimiu e unificou essas questões, além de revogar as Leis $\mathrm{n}$. 7.256/84 e 8.864/94 em seu art. 43.

Ainda nos anos 90 desse século, a Lei n. 9.317/96, que dispunha sobre o regime tributário das Microempresas e das Empresas de Pequeno Porte, acabou por instituir o Sistema Integrado de Pagamento de Impostos e Contribuições das Microempresas e das Empresas de Pequeno Porte (SIMPLES) e dando outras providências.

Essa Lei Tributária foi alterada pela Lei n. 9.732/98 e pela Lei n. 9.779/99, que tratou de hipóteses de exclusão do SIMPLES e outras matérias de ordem tributária. Prosseguindo no trabalho de criação de normas específicas, o legislador brasileiro preferiu se dedicar à parte tributária, das quais temos as Leis n. 10.034/00; 10.637/02; 10.964/04 e 11.051/04, sendo todas essas leis com foco no SIMPLES.

\subsubsection{Avanços normativos que} beneficiam a Microempresa e a Empresa de Pequeno Porte no Novo Milênio

O Novo Milênio foi contemplado com mais avanços normativos que beneficiam a Microempresa e a Empresa de Pequeno Porte, especialmente após a mobilização liderada pelo Serviço Brasileiro de Apoio à Micro e Pequenas Empresas (SEBRAE).

Em realidade, verificara que o Estatuto Federal da Microempresa e Empresa de Pequeno Porte, criado por lei ordinária federal estava limitado somente à esfera federal, portanto não tinha poder 
legislativo sobre os Estados e Municípios, o que comprometia o apoio.

O Código Civil de 2002 estabeleceu na Teoria da Empresa, em seu art. 970, que a lei deve assegurar "tratamento favorecido, diferenciado e simplificado ao empresário rural e ao pequeno empresário, quanto à inscrição e aos efeitos daí decorrentes".

A Emenda Constitucional n. 42/2003, publicada no último dia desse ano, propôs mudanças significativas no Sistema Tributário Nacional. De acordo com o art. 146, III, alínea "d" da CF, caberia à lei complementar fixar normas gerais sobre a "definição de tratamento diferenciado e favorecido para as Microempresas e para as Empresas de Pequeno Porte, inclusive regimes especiais ou simplificados".

Essas mudanças incidiriam no caso do imposto de ICMS, das contribuições a cargo do empregador, da empresa e entidade a ela equiparada, e da contribuição referente ao PIS/Pasep. Mas essa Emenda previu, nesse mesmo artigo, que uma lei complementar poderia instituir um regime único de arrecadação dos impostos e contribuições da União, dos Estados, do Distrito Federal e dos Municípios.

Diante dessa proposta na Emenda Constitucional, em 2005, sob a liderança do Sebrae, foi organizado o movimento da "Frente Empresarial pela Lei Geral da Micro e Pequena Empresa", com o objetivo de promover o engajamento das entidades de representação do setor produtivo no processo de elaboração e aprovação dessa Lei Complementar.

\subsubsection{Conquista das Microempresas e} Empresas de Pequeno Porte pela Lei Complementar n. 123/2006 e sua inclusão nas licitações eletrônicas das Compras Governamentais na esfera Federal

Vários Projetos de Lei Complementar surgiram para regulamentar a matéria, mas, em 2006, o projeto de Lei Geral aceito pelo movimento acabou sendo aprovado pela Câmara dos Deputados com algumas emendas, como Projeto de Lei Complementar n. 123/2004, em seguida pelo Senado como Projeto de Lei Complementar n. 100/2006, sendo posteriormente sancionado pelo Presidente da República como Lei Complementar n. $123 / 2006$, publicada no dia seguinte. Somente o capítulo tributário da lei (Simples Nacional) passou a vigorar em julho de 2007.

No mesmo ano, houve aprovação da Lei 11.598/2007, que estabeleceu diretrizes e procedimentos para a simplificação e integração do processo de registro e legalização de empresários e de pessoas jurídicas. Ela criou a Rede Nacional para a Simplificação do Registro e da Legalização de Empresas e Negócios (REDESIM).

A Lei Complementar n. 123/06 contribuiu para regulamentar o tratamento diferenciado às Microempresas e Empresas de Pequeno Porte, previsto como princípio no artigo 170, inciso IX da Constituição Federal, bem como para dar efetividade a outro comando inserido no artigo 179 da mesma Carta Magna. Foram criados dois benefícios por meio dessa Lei: (1) regularização fiscal exigida apenas para fins de contrato; (2) preferência no desempate.

Em relação ao primeiro, nas licitações públicas, a comprovação de regularidade fiscal das microempresas e empresas de pequeno porte somente será exigida para efeito de assinatura do contrato. No que tange ao segundo benefício, ele também tem proteção constitucional. $\mathrm{O}$ artigo $5^{\circ}$, caput, da Constituição Federal estabelece que "todos são iguais perante a lei".

O inciso XXI do artigo 37 dessa Carta Magna também confirma "igualdade de condições a todos os concorrentes". Da mesma forma, o artigo $3^{\circ}$ da Lei 8.666/93 impõe que a igualdade de tratamento entre os licitantes precisa ser observada em face do principio do "tratamento favorecido", insculpido nos artigos 170 , inciso IX, e 179 da Constituição Federal. 
Como lei benéfica ao micro e pequeno empresário, por facilitar a participação em processos licitatórios, ela também cumpre função social e beneficia o mercado local, além de manter empregos e gerar renda para a região. Contribui para manter o micro e pequeno em igualdade de competitividade com o grande empresário. Portanto todas as empresas de Pequeno Porte (EPP) ou Microempresas (ME) têm presença mais assegurada no vencimento dos certames, seja por meio do critério de desempate, ou da preferência de contratação para as microempresas e empresas de pequeno porte.

$\mathrm{O}$ enquadramento como Microempresas ou Empresa de Pequeno Porte está previsto no artigo $3^{\circ}$ da Lei Complementar 123/2006. Ela busca suporte no Código Civil para o conceito de empresário e na Constituição para o tratamento diferenciado de acordo com o artigo 966 do Código Civil.

Art. 966. Considera-se empresário quem exerce profissionalmente atividade econômica organizada para a produção ou a circulação de bens ou de serviços.

Parágrafo único. Não se considera empresário quem exerce profissão intelectual, de natureza científica, literária ou artística, ainda com o concurso de auxiliares ou colaboradores, salvo se o exercício da profissão constituir elemento de empresa.

Destaque deve ser dado aqui também ao Decreto 6204/2007, que regulamentou o tratamento favorecido, diferenciado e simplificado para as microempresas e empresas de pequeno porte nas contratações públicas de bens, serviços e obras, no âmbito da Administração Pública Federal.

De acordo com Pereira Jr. e Dotti (2008), foram previstos quatro instrumentos para ampliar as oportunidades de acesso da Microempresas e Empresas de Pequeno Porte aos contratos administrativos: a) prazo especial para comprovação de regularidade fiscal, próprio da fase da habilitação do procedimento licitatório; b) empate ficto com a proposta da empresa de maior porte, isso se o valor da proposta da Microempresa ou Empresa de Pequeno Porte for até $10 \%$ superior ao daquela, ou de até $5 \%$ na modalidade pregão; c) emissão de cédula de crédito micro empresarial pela micro ou pequena empresa que, sendo titular de direito a crédito empenhado e liquidado, não o receba em pagamento pela Administração em até trinta dias, contados da data da liquidação; e d) concessão de tratamento diferenciado e simplificado por meio do qual as pequenas e micro empresas podem disputar licitações destinadas exclusivamente a elas.

Por meio desse decreto, entende-se que a Microempresa ou Empresa de Pequeno Porte que for mais bem classificada pode apresentar proposta de preço inferior àquela considerada vencedora do certame, situação em que será adjudicado em seu favor o objeto licitado.

No ato do Pregão, em caso de ser a empresa Microempresa ou Empresa de Pequeno Porte a ganhadora do certame e alguma certidão esteja vencida, de acordo com a Lei Complementar n. 123/2006 e no prazo de até dois dias úteis, ela pode providenciar as certidões negativas. Ainda, se as microempresas ou empresas de pequeno porte no decorrer do contrato firmado com a Administração Pública se desenquadrarem desse tipo de empresa, não ocorrerá nenhuma mudança no contrato já firmado anteriormente. Conforme Fazzio Jr. (2008):

$\mathrm{O}$ enquadramento de firma comercial ou individual ou de pessoa jurídica em microempresa ou empresa de pequeno porte, bem como o seu desenquadramento, não implicará alteração, denúncia ou qualquer restrição em relação a contratos por elas anteriormente firmados. 


\section{MICROEMPRESAS E EMPRESAS DE PEQUENO PORTE E AS NOVAS PERSPECTIVAS DE PARTICIPAÇÃO NAS COMPRAS GOVERNAMENTAIS}

Diante da potencialidade do poder de consumo do Estado para induzir novos padrões de oferta de bens e serviços, o Comprasnet, entre 2010 e 2013, passou a adotar critérios de sustentabilidade no ato das compras feitas pelos órgãos públicos da instância Federal. Faz isso, exigindo em suas contratações, que os bens e serviços adquiridos estejam dentro desses padrões. Num outro viés, a nova Lei Complementar n. 147/2014 apresenta perspectivas de atribuir maior efetividade à inclusão da Microempresa e Empresa de Pequeno Porte nesse processo de compras governamentais.

\subsection{Contratações públicas sustentáveis}

A compra de produtos passa a levar em conta não só critérios econômicos e sociais, estes já realizados com a inclusão das Microempresas e Empresas de Pequeno Porte, mas também critérios ambientais.

Para esse fim, o Governo Federal propôs o Programa de Contratações Públicas Sustentáveis, iniciado em 2010. Esse programa foi ampliado e se fortaleceu após a aprovação do Decreto no 7.746, de junho de 2012. Ele estabelece que órgãos e entidades da Administração Pública Federal direta, autárquica e fundacional podem adquirir bens e contratar serviços e obras, utilizando-se dos critérios e práticas de sustentabilidade, desde que justificados e estabelecidos no edital da contratação ou compra.

Um estudo sobre a eficácia das compras públicas sustentáveis pelo governo federal foi realizado por Silva (2014) na UFMS. Para esse fim, foram analisadas as aquisições de produtos com critérios sustentáveis e o perfil de empresas que fornecem produtos sustentáveis para o Governo Federal, no banco de da- dos oficial de aquisições de produtos (Comprasnet).

Foi possível constatar que as Microempresas e Empresas de Pequeno Porte já representavam $54 \%$ do total de cadastros e responderam por $26 \%$ do montante negociado, e que chegaram a angariar mais de 15 bilhões de reais em cada período pesquisado. Assim, as Microempresas e Empresas de Pequeno Porte já detinham o dobro de representatividade e mobilizaram $58 \%$ do total de recursos negociados.

No entanto verificou também que a inserção das compras públicas sustentáveis realizadas pelos órgãos de administração pública federal ainda é muito pequena. Representava apenas $1,40 \%$ dos certames. No entanto a evolução desse processo vinha avançando de forma rápida. Em termos de recursos negociados, havia dobrado e já significava $68 \%$ no volume de licitações realizadas (SILVA, 2014).

\subsection{Perspectivas para as Microempresas e Empresas de Pequeno Porte em compras governamentais pela nova Lei Complementar}

Novas modificações legais ocorreram na busca de melhorias da Lei Geral da Micro e Pequena Empresa (Lei Complementar n. 123/2006). Em agosto de 2014, a Lei Complementar n. 147/2014 alterou alguns dispositivos da Lei Complementar n. 123/2006 e dispôs sobre o Simples Nacional.

Têm sido consideradas por vários autores um grande avanço ao desenvolvimento da Microempresa e Empresa de Pequeno Porte em nível nacional, por sua efetividade. Estas passaram mais a efetivamente usufruir das vantagens competitivas pertinentes ao campo das licitações.

No artigo 47 da Lei Complementar n. 123/2006, o tratamento diferenciado e simplificado nas contratações públicas, seja da União, Estados ou Municípios, 
seria concedido, "se previsto e regulamentado na legislação de cada um desses entes".

Portanto não eram efetivamente aplicáveis. Na nova Lei Complementar de 2014, esse último texto foi extraído, além de se acrescentar um novo na forma de parágrafo único.

Com as alterações apresentadas pela lei Complementar n. 147/2014 (BRASIL, 2014), foi excluído do texto do artigo 47 a disposição "desde que previsto e regulamentado na legislação do respectivo ente" e ainda foi incluída nova orientação junto ao parágrafo único que garante sua aplicação em outras instâncias, além da Federal. Conforme transcrevemos abaixo:

Art. 47. Nas contratações públicas da administração direta e indireta, autárquica e fundacional, federal, estadual e municipal, deverá ser concedido tratamento diferenciado e simplificado para as microempresas e empresas de pequeno porte objetivando a promoção do desenvolvimento econômico e social no âmbito municipal e regional, a ampliação da eficiência das políticas públicas e o incentivo à inovação tecnológica.

Parágrafo único. No que diz respeito às compras públicas, enquanto não sobrevier legislação estadual, municipal ou regulamento específico de cada órgão mais favorável à microempresa e empresa de pequeno porte, aplica-se a legislação federal. (BRASIL, 2014)

Também na Lei Complementar anterior, não existia obrigatoriedade desses entes em conceder tratamento diferenciado e simplificado à Microempresa e Empresa de Pequeno Porte. O termo "poderá" foi substituído no texto por "deverá", garantindo essa obrigatoriedade. Desse modo, esperam-se novas perspectivas de ampliação da participação da Microempresa e Empresa de Pequeno
Porte nos processos licitatórios no âmbito dos Estados e Municípios.

Na Lei Complementar anterior, a Microempresa e a Empresa de Pequeno Porte só poderiam participar de licitações cujas contratações não excedessem oitenta mil reais e o valor licitado não podia exceder a vinte e cinco por cento em cada ano civil. A nova Lei Complementar retirou essa última exigência dos vinte e cinco por cento de limite quantitativo anual. Ela exigia um planejamento diário muito difícil de ser estabelecido pela ME e EPP.

Na nova Lei, o estabelecimento de “cota de até $25 \%$ (vinte e cinco por cento) do objeto para a contratação de microempresas e empresas de pequeno porte, em certames para aquisição de bens e serviços de natureza divisível" (BRASIL, 2014) também tornou-se obrigatório. Além disso, foi acrescentada à referida Lei a prioridade que pode ser dada à Microempresa e Empresa de Pequeno Porte sediada no local e região até dez por cento do melhor preço válido.

A Lei Complementar n. 147/2014 dá autorização para que empresas prestadoras de serviços intelectuais, de natureza técnica ou científica, optem pelo Simples Nacional a partir de 2015.

Também podem optar pelo Simples Nacional as empresas de produção e comércio atacadista de refrigerantes, fisioterapia, corretagem de seguros e serviços advocatícios constituídas após a regulamentação da Lei Complementar n. 147/2014.

Microempresas e Empresas de Pequeno Porte com débitos ou pendências tributárias poderão ser baixadas perante os respectivos órgãos de registro, desde que haja responsabilização solidária dos empresários, titulares, sócios e dos administradores no período da ocorrência dos respectivos fatos geradores. 


\section{CONSIDERAÇÕES FINAIS}

Se as ferramentas eletrônicas do Pregão tornaram o Processo Licitatório das compras governamentais mais transparente e ágil, possibilitaram ainda igualdade de acesso a todos os portes empresariais, por outro lado, o potencial de compras governamentais tem permitido direcionar políticas públicas de interesse nacional, de natureza inclusiva, sustentável e inovadora.

Num outro viés, o segmento econômico da Microempresa e Empresa de Pequeno Porte tem-se mostrado estratégico e relevante, quando visto de forma diferenciada como integrante do conjunto de fornecedores, em processos licitatórios do governo.

Antes de existir a modalidade do pregão, um processo de compras governamentais podia durar facilmente em torno de quatro meses. Ao tornar o processo de compras mais transparente e ágil, o Pregão Eletrônico abriu o leque de participação empresarial para todo o país. Empresas de qualquer porte e localidade, que não a de seu domicílio, podem participar on-line, via internet, sem a necessidade de se deslocar até o órgão licitante e em igualdade de condições.

A dimensão jurídica representada pelas proposições normativas que se associam a essas dimensões tecnológicas, econômicas e políticas, como se pôde apreciar neste estudo, vem contribuindo para ampliar essas possibilidades impulsionando processos de desenvolvimento socioeconômico e ambiental no país.

A Lei Complementar n. 123/2006 alterada pela Lei Complementar $n$. 147/2014, que instituiu o Estatuto das Micro e Pequenas Empresas, foi de suma importância para os benefícios conquistados por esse segmento econômico. A Microempresa e a Empresa de Pequeno Porte não tinham tido, até então, a oportunidade de concorrer de igual para igual com as grandes empresas. Essa Lei foi fundamental para lhes abrir o mercado de licitações do Governo Federal e lhes possibilitou vantagens nunca antes concedidas.

A Lei n. 8.666/93 e a Lei Complementar n. 123/2006, alterada pela Lei Complementar n. 147/2014, por seu turno, contribuíram para dotar de maior transparência os gastos com o dinheiro público com menor custo na aquisição de materiais e serviços, além de maior participação das Microempresas e Empresas de Pequeno Porte nas licitações. Pautada em princípios constitucionais, proporcionou maior isonomia entre os empresários. Desse modo, mesmo que tenha iniciado suas atividades recentemente, um empresário consegue concorrer com empresário já estabelecido há mais tempo no mercado.

Se a Lei n. 8.666/93 e Lei Complementar n. 123/2006 já tinham trazido fortes contribuições ao desenvolvimento econômico e social do país, com políticas federais de natureza inclusiva e sustentável de micro e pequenas empresas, a nova Lei Complementar n. 147/2014 tem se apresentado como uma proposição jurídica com maiores perspectivas de avanços nas práticas do uso do poder de compras governamentais para incrementar esse processo. Essa lei tenta garantir maior efetividade às políticas de desenvolvimento desse segmento econômico de importante função social, expandindo as práticas utilizadas da instância Federal para a estadual e municipal.

Entende-se que o governo já esboçou uma política estratégica ambiental, ao incentivar os órgãos públicos a efetuarem compras governamentais sustentáveis. No entanto, se não houver o devido rigor por parte do próprio governo em sua aplicação, acabará sendo apenas mais uma legislação que nasce morta. Nesse sentido, precisam ser mais valorizados os grupos de trabalho permanentes inter e intragovernamentais capazes de atribuir maior solidez à aplicabilidade da legislação, tornando a compra de determinados itens obrigatória dentro das normatizações de sustentabilidade. 


\section{REFERÊNCIAS}

BRASIL. Lei $n$. 8.666/1993, de 21 de junho de 1993. Regulamenta o art. 37, inciso XXI, da Constituição Federal, institui normas para licitações e contratos da Administração Pública e dá outras providências. Diário Oficial da União, Seção 1, de 22 de junho de 1993.

Lei $n$. 10.520/2002, de 17 de julho de 2002. Institui, no âmbito da União, Estados, Distrito Federal e Municípios, nos termos do art. 37, inciso XXI, da Constituição Federal, modalidade de licitação denominada pregão, para aquisição de bens e serviços comuns, e dá outras providências. Diário Oficial da União n. 137, Seção 1, de 18 de julho de 2002.

Decreto n. 5.450 de 31 de maio de 2005. Regulamenta o pregão, na forma eletrônica, para aquisições de bens e serviços comuns, e dá outras providências. Diário Oficial da União, Seção 1, de $1^{\circ}$ de junho de 2005.

. Lei Complementar n. 123/2006, de 14 de dezembro de 2006. Institui o Estatuto Nacional da Microempresa e da Empresa de Pequeno Porte; altera dispositivos das Leis n. 8.212 e 8.213 , ambas de 24 de julho de 1991, da Consolidação das Leis do Trabalho - CLT, aprovada pelo Decreto-Lei n. 5.452 , de $1^{\circ}$ de maio de 1943, da Lei n. 10.189, de 14 de fevereiro de 2001. Diário Oficial da União, Seção 1, de 15 de dezembro de 2006.

Lei Complementar n. 147/2014, de 7 de agosto de 2014. Altera a Lei Complementar n. 123, de 14 de dezembro de 2006, e as Leis n. 5.889 , de 8 de junho de 1973, 11.101, de 9 de fevereiro de 2005, 9.099, de 26 de setembro de 1995, 11.598, de 3 de dezembro de 2007, 8.934, de 18 de novembro de 1994, 10.406, de 10 de janeiro de 2002, e 8.666, de 21 de junho de
1993; e dá outras providências. Diário Oficial da União, Seção 1, de 8 de agosto de 2014.

. Constituição da República Federativa do Brasil. Brasília: Casa Civil, 1988.

FAZZIO JR., Waldo. Manual de Direito Comercial. 9. ed. São Paulo: Atlas, 2008.

GASPARINI, Diógenes. Direito administrativo. 11. ed. São Paulo: Saraiva, 2006.

MEIRELLES, Hely Lopes. Direito administrativo brasileiro. 23. ed. São Paulo: Malheiros, 1998.

MOTA JR., João Francisco. O estatuto geral das microempresas e empresas de pequeno porte brasileiro - a nova lei complementar $\mathrm{n}$. 123/2006. Revista Derecho y Cambio Social, n. 11, ag. 2007.

PEREIRA JR., Jessé Torres; DOTTI, Marinês Restellato. $\mathrm{O}$ tratamento diferenciado às microempresas, empresas de pequeno porte e sociedades cooperativas nas contratações públicas, segundo as cláusulas gerais e os conceitos jurídicos indeterminados acolhidos na Lei Complementar n.123/06 e no Decreto Federal n.6.204/07. BCL: Boletim de licitações e Contratos, v. 21, n. 7, p. 667, jul. 2008.

SCARPINELLA, Vera. Licitação na modalidade de pregão. São Paulo: Malheiros, 2002.

SILVA, Raony Grau. Análise da eficácia das compras públicas sustentáveis do governo federal. 2014. Dissertação (Mestrado em Administração) - Universidade Federal de Mato Grosso do Sul. Campo Grande, MS.

SQUEFF, Flávia de Holanda Schmidt. O poder de compras governamental como instrumento de desenvolvimento tecnológico: análise do caso brasileiro. Brasília, DF: IPEA, jan. 2014. Disponível em: <http:/ /www.ipea.gov.br/ portal/images/stories/PDFs/TDs/td_1922. pdf>.

\section{Sobre os autores:}

Marcos André da Silva Cunha: Mestrando em Desenvolvimento Local pela Universidade Católica Dom Bosco (UCDB), Especialista em Gestão Empreendedora de Negócios pela Universidade da Grande Dourados (Unigran), Administrador, Bacharel em Direito, Servidor Público Federal da Fundação Universidade Federal de Mato Grosso do Sul, lotado na CGM/PRAD.. E-mail: admmasc@gmail.com

Cleonice Alexandre Le Bourlegat: Professora no Programa de Pós-Graduação em Desenvolvimento Local da Universidade Católica Dom Bosco (UCDB), Campo Grande, MS. E-mail: rf25@ucdb.br 